\title{
ANALISIS DESAIN FORMULIR RESUME MEDIS DI RSUD KOTA SALATIGA
}

\author{
Siti M asrochah1, Subinarto², Lina Umboro Setyowati ${ }^{3}$ \\ 1,2,3] urusan R ekam M edis dan Informasi K esehatan Poltekes K emenkes Semarang \\ E-mail : rmik@ poltekkes-smg.ac.id
}

\begin{abstract}
Medical records aimed at the orderly administration in an effort to improve heal th services in the hospital. One of the forms used in the inpatient medical record service is a medical resume. The medical resume formin hospitals Salatiga still did not agree with the theory, from the aspect of anatomy, physical and contents. This study aimed to analyze the design of medical resume form in Salatiga City Hospital fromthe aspect of anatomy, physical and contents. And also provide design solutions design medical resume form accordingly. This type of research is descriptive qualitative research. This research was conducted in Salatiga City Hospital on May 19 to May 26 in 2016, using the method of observation, interviews, documentary studies and FGD (Focus Group Discussion). Data processing techniques used in this study is reduction, display, conclusion drawing and verification. Observations based design medical resume form in Salatiga City Hospital that aspect has not been included heading anatomy complete form and lack of instruction. From the physical aspect is not well seen from the still opaque paper with a weight of 60 grams. Whileaspects of the content has been effective because it has provided to record the necessary data to the back of the form, but there has been no cause of death certificates.
\end{abstract}

K eywords: medical resume Form, Design, Salatiga City Hospital

\begin{abstract}
Abstrak
Rekammedis bertujuan untuk tertibadmi nistrasi dal amrangkaupaya peningkatan pelayanan kesehatan d rumah sakit. Sal ah satu formul ir yang digunakan dal am pelayanan rekam medis rawat inap adal ah Formul ir Resume Medis. Resume Medis di RSUD Kota Salatiga masih belum sesuai dengan teori, dari aspek anatomi, fisik dan isi. Penelitian ini bertujuan untuk menganalisis desain Resume Medis di RSUD Kota Sal atiga ditinjau dari aspek anatomi, fisik dan isi. Dan juga memberikan solusi rancangan desain Resume Medis yang sesuai. Jenis penelitian yang digunakan adalah penelitian deskriptif dengan pendekatan studi kasus. Penelitian ini dilaksanakan di RSUD Kota Sal atiga pada tanggal 19 Mei sampai tanggal 26 Mei tahun 2016, dengan menggunakan metode observasi, wawancara, studi dokumentasi dan juga FGD (Focus Group Discusion). Pengolahan data pada penelitian ini adalah reduksi data, penyajian data, penarikan kesimpulan dan verifikasi. Hasil pengamatan berdasarkan desain Resume Medis di RSUD Kota Salatiga bahwa aspek anatomi belum mencantumkan heading formulir yang lengkap dan belum adanya instruction. Dari aspek fisik belum baik dilihat dari kertas yang masi h buram dengan berat 60 gram Sedangkan dari aspek isi sudah ef ektif karena sudah di sediakan untuk merekam data yang diperlukan namun untuk bagian belakang formulir belum ada sertifikat sebab kematian.
\end{abstract}

Kata K unci: Desain Formulir Resumemedis, RSUD Kota Salatiga

\section{PENDAHUL UAN}

Rekam medis merupakan kumpulan fakta tentang kehi dupan seseorang, dan riwayat penyakitnya, termasuk keadaan sakit dan pengobatan saat ini dan saat lampau yang ditulis oleh praktisi kesehatan dalam upaya mereka memberikan pelayanan kesehatan kepada pasien. (Hatta, 2010) Pengelolaan rekam medis yang baik dan benar akan mendukung tertib administrasi sehingga sesuai yang di harapkan.
Fungsi rekam medis meliputi aspek administrasi, medis, hukum, keuangan penelitian, pendidikan dan dokumentasi juga menjadi alasan yang kuatmengapa rekam medis harus dibuat. Untuk mencapai tujuan tersebut rekam medis di tunjang oleh beberapa sub sistem, yang meliputi Filling, Coding, Assembling, Indexing. Data-data medis yang terdapat pada berkas rekam medis pasien selanjutnya akan diolah untuk menghasilkan informasi yang berguna bagi 
pihak manajemen rumah sakit dalam menetapkan kebijakan dan pengambi lan keputusan dalam tahap perencanaan, pelaksanaan dan pengelolaan serta evaluasi terhadap hal-hal yang berkaitan dengan pel ayanan yang diberikan. Sal ah satu formulir rekam medis yang digunakan dalam penyelenggaraan pel ayanan rekammedis di rawat inap adalah Resume Medis. Dan juga Resume Medis adalah formulir yang diabadikan. Resume Medis adalah formulir yang berisi informasi tentang identitas pasien, cara penerimaan melalui cara masuk dikirim oleh, serta berisi ringkasan data pada saat pasien keluar, lihat lembaran ini merupakan sumber informasi untuk mengindeks rekammedis, sertamenyiapkan laporan rumah sakit. Ada beberapa formulir di RSUD kota Sal atiga antara lain formulir resume medis, resume, formulir asuhan keperawatan, laboratorium, formulir operasi. Data yang tercatat dal am Resume Medismeliputi data identitas dan data klinis. Yang berhak mengisi identitas adalah petugas pendftaran serta data klinis adalah dokter. Berdasarkan hasil pengamatan yang peneliti lakukan, Resume Medisdi RSUD kota Salatiga untuk formulir yang sudah disimpan lebih dari lima tahun tulisan pada formulir sudah tidak terbaca lagi. Para pengguna formulir kesulitan untuk memilih atau mengisi formulir. Ada formulir yang terlubangi saat proses penyimpanan dalamdokumen. Petugas rekammedis menul iskan nomor rekammedis pasien pada kolom nomor register pasien. Petugas rekam medis harus membuat formulir sebab kematian pada kertas yang berbeda untuk pasien yang meninggal. Berdasarkan latar belakang tersebut, penul is berkeinginan untuk menganalisis desain Resume Medis di RSUD Kota Salatiga. Oleh karenaitu, pada penelitian ini penul is memilih judul "Analisis Desain Formulir Resume Kesehatan di RSUD Kota Sal atiga".

\section{METODE}

J enisPenelitianini peneliti adalah deskriptif kual itatif. Metode penelitian yang digunakan: Observasi, wawancara, studi dokumentasi. Teknik Pengolahan Data yang digunakan dalam penelitian ini adalah reduksi, penyajian data, penarikan kesimpulan. Reduksi data merupakan proses merangkum, memilih hal-hal yang pokok, menfokuskan pada hal yang penting untuk memberikan gambaran yang lebih jelas dan mempermudah peneliti untuk melakukan pengumpul an data sel anjutnya, dan mencarinya bila diperlukan. Setelah data direduksi, maka selanjutnya data disajikan dalam bentuk teks yang bersifat naratif. Langkah selanjutnya adalah penarikan kesimpulan dan interpretasi data. Interpretasi data dilakukan dengan menghubungkan hasil analisis dari penelitian dengan teori yang relevan tentang standar pengelolaan waktu pengembal ian dokumen rekam medis rawat inap, sehingga dapat menjawab pertanyaan dari permasal ahan-permasalahan penel itian yang ada dan dapat memberikan masukan bagi perbaikan tentang desain Resume Medis.

\section{HASIL DAN PEMBAHASAN}

\section{Aspek anatomi Resume Medis di RSUD Kota Salatiga.}

\section{Heading(K epala)}

Menurut Indradi S (2013), bagi an kepala (heading) meliputi judul (nama) formulir, subjudul, nama institusi (rumah sakit, puskesmas dan sebagainya), logo, nomor kode dan revisi, nomor halaman dan informasi lengkap lainnya. Heading ini bisa ditempatkan di bagian atas atau sisi kanan formulir. Semua formulir dalam suatu institusi hendaknya memiliki posisi dan komposisi heading yang sama. Posisi heading mempertimbangkan aspek penjilidan, penyimpanan, palipatan, dan penataan formulir.

Hasil observasi judul Resume Medisdi RSUD Kota Salatiga terletak disebelah tengah atas, namun untuk identitas rumah sakit hanya tertera nama rumah sakit tanpa identitas lainnya seperti alamat, nomor telepon, dan juga logo rumah sakit. Dan juga informasi lain bel umada seperti tanggal penerbitan. Penulis mengusul kan untuk menambahkan itempada heading formulir yang meliputi, identitas rumah sakit seperti nama, alamat, nomor tel epon, faks, website, email dan logo RSUD Kota Salatiga. Dan juga terdapat judul formulir, nomor halaman dan tahun revisi formulir.

\section{Introduction (Pendahuluan)}

Menurut Indradi S (2013), bagian pendahuluan (introduction) berisi keterangan tambahan mengenai formulir. J ika memang bagi an headi ng sudah cukup menggambarkan fungsi dan tujuan formulir tersebut maka tidak perlu lagi ditambahkan introduction ini. Bagian Introduction (pendahuluan) pada Resume Medisdi RSUD Kotas Salatiga ditunjukkan pada identitas pasien yang meliputi nama, umur, jenis kelamin, agama, nomor register, pendidikan, pekerjaan, status, dan tanggal masuk dan keluar. Berdasarkan hasil diskusi perlu item tambahan berupa bahasa primer atau bahasa keseharian yang 
digunakan oleh pasien, karena di RSUD Kota Sal atiga dekat dengan universitas dan juga sekolah internasional.

\section{Instruction (Perintah)}

nstruction padaResumeMedi sdi RSUD KotaSalatiga belumada. Menunt Indradi (2013), Bagian perintah (instruction) berisi penjelasansingkattentang jumlah lembar, cara pengisian, cara pengiriman. Bagian ini biasanya diatur penempatannya agar jelas, singkat, danti dak mengganggual ur pembacaan dan pengisian formulir. Maka penulis mengusulkan instruction ditambahkan dan di letakkan pada bagian kiri bawah dari formulir resume medis.

\section{Body (Badan)}

Menurut Indradi S (2013), Bagian isi (body) merupakan inti dari suatu formulir. Di bagian inilah data dicatat. Penggunaan metode pengelompokan (grouping), urutan (sequence), bentuk dan ukuran huruf (font), wama area (color), batas tepi (margin), spasi (space), garis (lines) dan cara pengisian sangat berperan terhadap hasil pengisian formulir.

Metode pengelompokan (grouping) dalam Resume Medis RSUD KotaSalatiga di kelompokan menjadi 4 yaitu : identitas pribadi, identitas sosial, tindakan medis dan autentifikasi. Hal ini sudah sesuai denga teori. Urutan (sequence) dimulai dari identitas pribadi, identitas sosial, kegiatan medis kemudian paling bawah adalah autentifikasi. Jenis huruf yang digunakan pada Resume Medisdi RSUD Kota Salatiga ini adal ah Times New Roman dengan ukuran font 12. Ukuran tersebut sudah sesuai dengan teori. Warna area (color) berwarna puth. Hal ini sudah membuat tul isan yang berwarna gel ap terlihat jelas.

Berdasarkan hasil observasi sisi-sisi pada formulir atau margins formulir pada batas tepi kiri Resume Medisdi RSUD Kota Salatiga berukuran $1 \mathrm{~cm}$. Namun ResumeM Medisdi RSUD Kota Sal atiga perlu dilubangi pada sisi kiri karena untuk penyimpanan formulir pada map rekam medis pasien. Maka perlu ditambah lagi ruang untuk pembolong agar tidak mengenai garis terluar dari desain formulir resume medis.

Spasi yang digunakan pada formulir ini adal ah satu spasi . hal ini sudah efektif karena sudah disesuaikan dengan ukuran item-itemya sehingga tulisan dapat dibaca dengan jelas. Garis yang digunakan dalam Resume Medisdi RSUD Kota Salatiga ini adalah solid (langsung). Hal ini sudah sesuai dengan teori.
Pencatatan data pada Resume Medisdi RSUD Kota Salatiga adalah dengan cara menulis langsung dan juga pilihan. Namun caramenentukan pilihan belum seragam, karena ada pili han yang dicoret yang tidak perlu, dilingkari yang penting dan juga pili han cek list.

\section{Close(penutup)}

Menurut Indradi S (2013), Bagian penutup (close) merupakan bagian akhir dari suatu formulir namun memiliki arti yang sama pentingnya dengan bagianbagian sebel umnya. Padabagian ini tercantumtanda tangan, nama terang, keterangan tempat, tanggal dan jam bila diperlukan. Close pada formulir ini ditunjukkan pada bagian bawah yaitu pada bagian bawah terdapat nama dokter dan tanda tangan dokter. Namun perlu ditambahakan tempat dan tanggal pengisian. Karena menurut hasil diskusi perlu ditambahkan tempat, waktu pengisian dan catatan tambahan.

Aspek fisik formulir, meliputi pemikiran tentang bahan, bentuk, ukuran, warna.

Menurut Indradi S (2013), Jika berupa formulir kertas, hendaknya menggunakan kertas dengan kualitas yang baik dan tahan lama. Formulir rekam medis tidak boleh menggunakan kertas buram (baik yang berwamacoklatmaupun puth). Di RSUD Kota Salatigauntuk formul ir resumemedis, menggunakan kertas buram seberat $60 \mathrm{gr}$. Resume M edisberbahan tipis dan mudah rusak mengingat formulir tersebut bersifatabadi, sebai knya diganti dengan kertas HVS 80 gram agar lebih tahan lama untuk disimpan. Namun pada hasil diskusi menyatakan bahwa sebai knya menggunakankertasHVS 70 gramkarena mengingat anggaran yang masih kurang.

Menurut Indradi S (2013), jika berupa formulir kertas, hendaknya semua formulir memiliki ukuran yang sama dan standar, bi asanya A4. Resume Medisdi RSUD KotaSalatigamemiliki ukuran yang sama dengan formul ir yang lain yaitu ukuran kertas folio. Setiap lembar formulir harus mencantumkan identitas pasien, minimal berupaitem "namapasien" dan "nomor rekam medis". Jika formulir tersebut bolak balik, maka item identitas pasien ini harus dicantumkan pada kedua sisi formulir tersebut. ResumeM edisdi RSUD KotaSal atiga terdapatnama pasien pada bagian depan saja. Untuk bagian depan dan belakang tidak terdapat nomor rekam medis. Menurut Indradi S (2013), warna dasar formulir hendaknya putih atau warna muda lai nnya untuk 
menjaga nilai kontras antara warna dasar formulir dengan wamatintanya. ResumeMedisdi RSUD Kota Salatiga menggunakan warna dasar putih tulang. Namun pada hasil usulan desain penulis, penulis memnggunakan kertas putih bersih agar tulisan terlihat lebih jelas.

\section{Aspek pengisian formulir}

Menurut I ndradi S (2013), upayakan sedi kitmungkin pengisian formulir dengan cara menulis langsung, upayakan pengisian dengan cara memilih, memberi tanda, dan sebagainya. pada Resume Medisdi RSUD KotaSalatiga ada item yang mengisi dengan menul is langsung dan memilih dengan memberi tanda. Hal ini sudah sesuai dengan teori, mengingat pengisian dengan caratul is langsung hanya pada item nama, alamat, tanggal lahir, diagnosa penyakit dan tindakan, sel ebi hnya dengan cara pilihan.

Menurut Indradi S (2013), upayakan meggunakan metode upper left caption (ULC) untuk menandai dan memberi keterangan pada setiap itemyang harus diisi. Penggunaan ULC biasanya bisa memperjelas dan menambah luas area pengisian. Pada Resume Medisdi RSUD Kota Salatiga sudah menggunakan metode upper left caption (ULC) untuk menandai dan memberi keterangan pada setiap item yang harus diisi. Dapat dilihat pada lampiran Resume Medissudah menggunakan metodeupper left caption (ULC).

Menurut Indradi S (2013), sediakan area (spasi) yang cukup untuk setiap item isian dan sesuai dengan cara pengisiannya (ditulis atau diketik). Berdasarkan hasil observasi spasi yang ada pada Resume Medisdi RSUD Kota Salatiga adalah 1 spasi. Berdasarkan hasil wawancara dengan ketiga responden menyatakan bahwa spasi pada kolom item sudah mencukupi. Berdasarkan pembahasan tersebut, penulis menggunakan 1 spasi untuk re desain Resume Medisdi RSUD Kota Salatiga. cantumkan keterangan cara pengisian yang jelas. Keterangan ini umumnya ditempatkan sebel umitem yang akan diisi. Pada Resume Medisdi RSUD Kota Salatiga tidak terdapat keterangan cara pengisian yang jelas. berdasarkan hasil wawancara terhadap responden menyatakan bahwa keterangan cara pengisian di letakkan pada bagian kiri bawah formulir resume medis.

\section{SIMPULAN}

Aspek anatomi dari Resume; identitasformulirhanya tertera nama rumah sakit. Identitas formulir terletak di sebelah kanan atas. Bagian instruction yang semulatidak ada, pada re desain formul ir diletakkan pada bagian kiri bawah formul ir. Untuk bagian body formul ir padasisi sebelah kiri di tambah ruang untuk pembolong guna penyimpanan formulir kedalam map. Bagian close ditambah dengan tempat dan waktu pengisian autentikasi. Aspek fisik dari Resume Medis; Bahan kertas formulir kertas HVS 70 gram. Untuk bentuk dan ukuran menyesuaikan dengan formulir yang lain seperti resume medis, laporan operasi, persetujuan rawat inap, informed consent dan formulir yang lainnya. Aspek pengisian formulir : ada item yang mengisi dengan menulis langsung dan memilih dengan memberi tanda. Untuk menandai dan memberi keterangan padasetiap itemyang harus di isi sudah menggunakan metode upper left caption (ULC). Menggunakan 1 spasi pada semua teks.

\section{DAFTAR PUSTAKA}

Harjiyanti, Sri. 2010. Tinjauan desain Formulir Ringkasan Masuk dan Keluar pasien rawat inap ditinjau dari aspek anatomi, isi dan fisik. Yogyakarta: Program Studi Rekam Medis dan Informasi Kesehatan, Sekolah Vokasi UGM Yogyakarata.

Hatta, G.R. 2010. Pedoman Manajemen Informasi Kesehatan di Sarana Pelayanan Kesehatan. Jakarta: Universitas Indonesia.

Sudra RI.2013. RekamMedis.Tangerang: UTPPress

Notoatmojo, Soekidjo. 2005. Metode Penelitian Kesehatan. Jakarta: Rineka Cipta

Rustiyanto, Ery. 2009. EtikaProfesi PerekamMedisdan Informasi Kesehatan. Yogyakarta: Grahallmu

Situmorang, Kurnia. 2008. Analisa Desain Formulir Anamnesa Dan Pemeriksaan Fisik Untuk Pencatatan Pasien Dengue Haemorrhagic. Yogyakarta: Program Studi Rekam Medis dan Informasi Kesehatan, Sekolah Vokasi UGM Yogyakarata. 